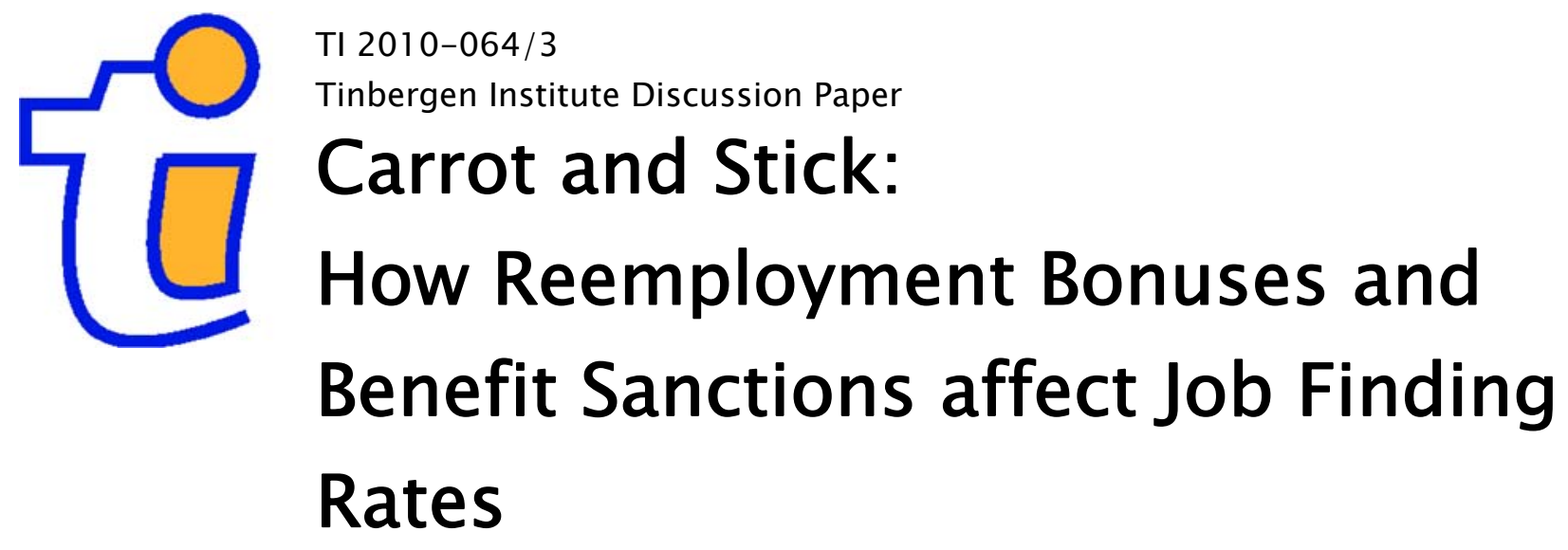

Bas van der Klaauw

Jan C. van Ours²

' VU University Amsterdam, and Tinbergen Institute;

${ }^{2}$ CentER, Tilburg University, University of Melbourne, Australia, CESifo, CEPR, and IZA. 


\section{Tinbergen Institute}

The Tinbergen Institute is the institute for economic research of the Erasmus Universiteit Rotterdam, Universiteit van Amsterdam, and Vrije Universiteit Amsterdam.

Tinbergen Institute Amsterdam

Roetersstraat 31

1018 WB Amsterdam

The Netherlands

Tel.: +31(0)205513500

Fax: $+31(0) 205513555$

Tinbergen Institute Rotterdam

Burg. Oudlaan 50

3062 PA Rotterdam

The Netherlands

Tel.: + $31(0) 104088900$

Fax: $+31(0) 104089031$

Most TI discussion papers can be downloaded at http://www.tinbergen.nl. 


\title{
Carrot and Stick: How Reemployment Bonuses and Benefit Sanctions Affect Job Finding Rates
}

\author{
Bas van der Klaauw * \\ Jan C. van Ours ${ }^{\dagger}$
}

July 7, 2010

\begin{abstract}
To increase their transition from welfare to work, benefit recipients in the municipality of Rotterdam were exposed to various financial incentives, including both carrots to sticks. Once their benefit spell exceeded one year, welfare recipients were entitled to a reemployment bonus if they found a job that lasted at least six months. However, they could also be punished for noncompliance with eligibility requirements and face a sanction, i.e. a temporary reducing of their benefits. In this paper we investigate how benefit sanctions and reemployment bonuses affect job finding rates of welfare recipients. We find that benefit sanctions were effective in bringing unemployed from welfare to work more quickly while reemployment bonuses were not.
\end{abstract}

Keywords: welfare to work, financial incentives, timing-of-events, dynamic selection, difference-indifference.

JEL-code: J64, C21, C41.

*Department of Economics, VU University Amsterdam; Tinbergen Institute, CEPR, IZA and IFAU; bklaauw@feweb.vu.nl

${ }^{\dagger}$ Department of Economics, CentER, Tilburg University, Netherlands; Department of Economics, University of Melbourne, Parkville, Australia; CESifo, CEPR and IZA; vanours@uvt.nl. 


\section{Introduction}

With the emerging financial crisis and rising unemployment governments consider various policy instruments to bring unemployed back to work. This is not easy. Traditional active labor market policies (ALMP) are often not very successful. In their overview study of 53 evaluation studies Kluve and Schmidt (2002) conclude that both direct job creation and employment subsidies in the public sector almost always seem to fail. Kluve (2010) follows up on this and presents an analysis of 137 ALMP evaluation studies in Europe, most of them operating after 1990. He finds that the effectiveness of programs is quite independent of contextual factors such as labor market institutions and macroeconomic environment. Traditional training programs appear to have at most a modest effect on transitions from unemployment to work. Direct employment programs in the public sector are rarely effective and frequently detrimental for the employment prospects of participants. Card et al. (2009) present an assessment of ALMP based on approximately 200 European and U.S. microeconometrics evaluations. The authors find that subsidized public sector employment programs are relatively ineffective. Job search assistance programs have a favorable impact especially in the short run while classroom and on-the-job training programs are not favorable in the short-run, but have more positive impacts after two years. The bottom line of these overview studies is that simple non-expensive programs with clear incentives for unemployed workers work best. This is not a new finding. On the basis of outcomes from four U.S. cash bonus experiments and six job search experiments Meyer (1995) concludes that economic incentives affect the speed by which unemployed workers leave the unemployment insurance rolls. Some of these job search experiments included enforcement of job search rules and administrative measures of enforcement such as denials of benefits.

In our paper we investigate how positive and negative financial incentives affect the outflow from welfare to work. The municipality of Rotterdam exposed welfare recipients to financial carrots as well as financial sticks, i.e. the incentives could have positive or negative effects on the income of benefit recipients. Benefits could be reduced temporarily as punishment for noncompliance with eligibility requirements. However, once their benefit spell exceeded one year, the welfare recipients were entitled to a bonus if they found a job that lasted at least six months. ${ }^{1}$

\footnotetext{
${ }^{1}$ In the Netherlands municipalities are responsible for providing welfare benefits. Comparing the way municipalities operate De Koning et al. (2006) find that to stimulate welfare recipients to find a job quickly Rotterdam uses benefit sanctions and reemployment bonuses more often than other municipalities.
} 
We use hazard rate models to identify the effects of both financial stimuli. Identification of the effect of benefit sanctions is based on the idea that welfare recipients cannot anticipate the exact moment of getting punished. We follow Abbring and Van den Berg (2003) and use of multivariate mixed proportional hazard models in which the potential selectivity in the use of benefit sanctions is accounted for by simultaneous modeling of the sanction rate and the job finding rate. Identification of the effect of reemployment bonuses is based on the variations in the bonus policy that occurred during our period of analysis. Since only a subsample of the welfare recipients are exposed to the bonus policy, there is a well-defined control group to separate calendar-time effects from the effects of the reemployment bonuses. Our contribution to the literature is twofold. First, we analyze the effect of reemployment bonuses in a recent non-U.S., non-experimental setting. So far, knowledge about the effect of reemployment bonuses is limited to a few 1980s pilot studies in the U.S. where benefits are relatively low and short-lasting. We analyze the effect of reemployment bonuses in recent years in the context of European style labor market institutions with relatively high benefits and long benefit durations. Second, we analyze financial incentives in a setting where unemployed workers are exposed to both positive and negative stimuli. As far as we know there are no other empirical studies who analyze the simultaneous effects of positive and negative financial incentives. We find that benefit sanctions are very effective while reemployment bonuses are not.

The setup of our paper is as follows. In section 2 we give an overview of previous studies on benefit sanctions and reemployment bonuses. Section 3 discusses financial incentives to which welfare recipients are exposed in Rotterdam. This section also provides a description of our data. In section 4 we present our statistical model, and in section 5 we discuss our estimation results from which we conclude that benefit sanctions speed up the transition from welfare to work while reemployment bonuses have no effect. In section 6 we provide an explanation of our main findings. Section 7 concludes.

\section{Previous studies}

\subsection{Benefit sanctions}

There are a couple of empirical studies that investigate the effects of benefit sanctions on job finding rates. Abbring et al. (2005) analyze how benefit sanctions in the Netherlands affected the job finding rates of unemployment benefits recipients. According to the Dutch 
Unemployment Insurance law there are three categories of infringements for which workers can have benefit sanctions imposed: lack of effort to find a job (search intensity too low, declining job offers), administrative infringements (reporting too late), and other infringements (fraud, inaccurate information). The sanction is a temporary or a permanent full or partial reduction of the benefit level. In practice, the temporary partial reduction of the benefits ranged from $5 \%$ during four weeks to 25 or $30 \%$ during 13 weeks. Abbring et al. find that reemployment rates are significantly and substantially raised by imposition of a benefit sanction. The increase in reemployment rate varies from 35 to $100 \%$ depending on industry and gender, where the effects for women are substantially larger than for men. Van den Berg et al. (2004) analyses the effects of sanctions on the behavior of welfare (benefits) recipients in Rotterdam. A welfare recipient has similar obligations as a unemployment benefit recipient in order to remain eligible for a benefit. The duration and size of the reduction depend on the nature of the infringement ranging from $5 \%$ during one month to $20 \%$ during four months. It turns out that when a benefit sanction is imposed the job finding rate more than doubles. The benefit sanction itself is temporary, but its effects turn out to be long lasting. Even after the sanction period expires the transition rate from welfare to work is higher than before the sanction was imposed. From an analysis of Swiss data on benefit sanctions Lalive et al. (2005) conclude that by imposing a benefit sanction the job finding rate to go up with $45 \%$ causing the unemployment duration to decrease with roughly three weeks from 33 to 30 weeks. Jensen et al. (2003) find a small effect of the sanctions that are part of Danish youth unemployment program. However, also using Danish data Svarer (2007) finds that the unemployment exit rate increases by more than $50 \%$ following enforcement of a sanction. Boockmann et al. (2009) investigate the effectiveness of benefit sanctions applied to welfare recipients in Germany. They use variation in sanction strategies and sanction rates across welfare agencies in an instrumental variable framework to account for potential selectivity in the use of benefit sanctions. They find that a sanction increases the probability of the welfare system within eight months after the benefit cut by about $70 \%$ points.

So, from previous studies it is clear that benefit sanctions speed up job finding, i.e. they have a positive "treatment" effect. The size of the penalty or the duration of the punishment doesn't seem to be important (Van den Berg et al., 2004). It could be monitoring that is driving the treatment effect rather than the sanction per se. Indeed, McVicar (2008) investigates the effect of monitoring on the duration of unemployment by exploiting periods of monitoring suspension during Benefit Office refurbishments in part of the UK. He finds that 
suspension of monitoring led to significantly lower exit rates from unemployment. Studies that distinguish between warnings and actual enforcement of benefit sanctions show that both matter (Lalive et al., 2005, and Arni et al., 2009).

Although most previous studies find positive treatment effects of benefit sanctions, these seem to come at a cost. As far as we know there are only two studies that investigate the effect of benefit sanctions on the quality of the post-unemployment job. Arni et al. (2009) evaluate the effects of benefit sanctions on post-unemployment employment stability, on exits from the labor market and on earnings. They find that both warnings and enforcement increase the job finding rate and the exit rate out of the labor force. Warnings do not affect subsequent employment stability but do reduce post-unemployment earnings. Actual benefit reductions lower the quality of post-unemployment jobs both in terms of job duration as well as in terms of earnings. For unemployed workers the net effect of a benefit sanction on postunemployment income is negative. Over a period of two years after leaving unemployment workers who got a benefit sanction imposed face an income loss equivalent to 30 days. Van den Berg and Vikström (2009) also study the post-unemployment effects of benefit sanctions. Using Swedish data they find that sanctions lower wages and hours of work and lead to a lower occupational level of post-unemployment jobs.

\subsection{Reemployment bonuses}

Woodbury and Spiegelman (1987) present an analysis of the first reemployment bonus experiments, conducted in Illinois, from mid-1984 to mid-1985. In this experiment a random sample of new UI (Unemployment Insurance) claimants were informed that they would qualify for a cash bonus of $\$ 500$ if they found of job of 30 hours or more per week within 11 weeks of filing the claim, and would hold that job for four months. In the second experiment a second random sample of new UI claimants was told that their next employer would qualify for a cash bonus if the claimants would find a job within 11 weeks and if they retained their job for four months. The authors find that the reemployment bonus in the first experiment reduced unemployment duration with approximately one week. The second experiment had a much smaller effect. The post-unemployment earnings of members of the treatment group didn't differ from the earnings of members of the control group. Another interesting finding concerns the take-up rate, i.e. the percentage of workers who qualified for the bonus and actually took the steps to claim it. The take-up rate in the first experiment was $54 \%$, while in the second experiment the take-up rate was as low as $12 \%$. Anderson (1992) presents 
an analysis of a New Jersey reemployment bonus experiment, conducted from mid-1986 to mid 1987. In this experiment UI claimants were randomly assigned to one of three treatment groups or a control group. All UI claimants in the treatment groups were assigned to job-search assistance activities. One group was offered a cash bonus for finding a new job, with the bonus declining over the unemployment spell falling to zero in the eleventh week of unemployment after the initial offer. A second group was offered assistance in getting into a job-training program while a third group was offered nothing. The author finds that the effect of a bonus on the job finding rate is significantly positive early in the offer period, when the bonus was largest. Decker (1994) compares the Illinois and New Jersey experiments focusing on the duration dependence of the reemployment bonus, which was constant in Illinois but declining in New Jersey. The author finds that the declining bonus offer in New Jersey affected relative short-term unemployed relative more while the constant bonus offer in Illinois had a substantial impact on longer-term unemployed. Decker and O'Leary (1995) analyze the results from reemployment bonus experiments conducted in 1988 and 1989 in Pennsylvania and Washington, which differed in the amount of the bonus offer and the period for which an individual qualified for the bonus. The Pennsylvania experiment tested four different bonus offers based on two alternative bonus amounts and two alternative qualification periods. The Washington experiment compared six different bonus offers based on three alternative bonus amounts and two alternative qualification periods. The authors find that more generous bonus offers generated larger impacts than did less generous offers but the overall effects are relatively modest. Both experiments reduced UI receipt by an average of about a week, while the impact on the post-unemployment earning was not statistically significant. O'Leary, Spiegelman and Kline (1995) also present an analysis of the Washington reemployment bonus experiment. They find that the strongest treatment response was exhibited by claimants who were offered a high bonus level with a long qualification period. For this treatment unemployment duration went down with 0.76 weeks. The results from the four U.S. reemployment bonus experiments have been reinvestigated a number of times. Meyer (1996) reexamines the results from the part of the Illinois reemployment bonus experiment in which the bonus was paid to UI recipients and focusing on the suitability of a reemployment bonus program for permanent adoption. According to Meyer, in a permanent program a larger fraction of workers that qualify for a bonus might complete the paperwork necessary to receive it. Furthermore, a permanent bonus program might encourage unemployed workers to file for UI. O'Leary, Decker and Wandner (2005) reexamine the Pennsylvania and Washing- 
ton experiments to investigate whether bonuses targeted to those most likely to exhaust UI benefits would be cost-effective. They find some evidence that targeting may be beneficial. ${ }^{2}$ All in all, there is a variety of outcomes of the reemployment bonus experiments depending on the details of the experiment but overall they seem to have had a positive but small effect on the job finding rates.

An interesting finding on the use of reemployment bonuses is the low take-up rate. As indicated before, in the Illinois experiment only $54 \%$ of the unemployed workers entitled to the bonus actually used it. Bijwaard and Ridder (2005) report that in the Illinois experiment of the eligible workers $15 \%$ refused participation, while of the eligible employers $35 \%$ refused participation. They find noncompliance to be selective. When this selectivity is taken into account the effects of the reemployment bonus are bigger.

Positive financial incentives seem to work. This is also the case when in stead of reemployment bonuses a temporary subsidy on earnings is provided to low income workers through in-work benefits. An example of this is the Canadian Self Sufficiency Project (SSP) which was introduced in the early 1990s and was intended to help welfare recipients to make a permanent break from welfare dependency. The subsidy scheme applied only to individuals who accepted full-time jobs, could last for up to three years, and once workers were offered the scheme they had to begin to work within a year. The SSP was evaluated using a randomized design. One-half of the long-term welfare recipients was offered the SSP while the other half remained in the regular welfare system. Data were collected for six years in order to measure both the short-term and the long-term effects of the subsidy scheme. Card and Hyslop (2005) show that indeed even for long-term welfare recipients earnings subsidies have a positive effect on employment rates. However, this is not a permanent effect.

Summarizing the literature on benefit sanctions and reemployment bonuses it is clear that financial incentives, irrespective whether they are positive or negative, increase job finding rates. The effect of benefit sanctions seems to be larger than the effect of reemployment bonuses.

\footnotetext{
${ }^{2}$ Bilias (2000) also reexamines the Pennsylvania reemployment bonus experiment but he focusses on the optimal duration of the experiment, i.e. the minimal time needed to draw sensible conclusions from the experiment and not on the outcomes of the experiment. He finds that conclusions about the effectiveness of the experiment could have been obtained much earlier than the end of the study as designed by the experimenters.
} 


\section{Financial incentives for welfare recipients in Rotterdam}

In the Netherlands, welfare benefits are a safety-net and provide support to unemployed workers who are not entitled to any other social insurance benefits like unemployment insurance or disability insurance benefits. Thus, welfare benefits recipients are often long-term unemployed with poor labor market prospects. Welfare benefits are means tested and related to the family situation, but not limited in duration. Benefit replacement rates are usually somewhat higher than in most other European countries and much higher than in the US (see for more details Van den Berg et al., 2004). Welfare recipient have an obligation to actively search for a job.

\subsection{Reemployment bonuses}

Under some conditions, welfare recipients in Rotterdam were entitled to reemployment bonuses. Such bonuses exist in Rotterdam since 1997. Over the period of our analysis 2000-2003 the main condition was that the individuals had to be on welfare benefits for at least one year. Furthermore, at the start of the job they had to be off benefits and the workers had to remain employed for at least six months. Even though the calendar period we consider is rather short, the reemployment bonus rules changed frequently. Since our inflow sample starts on the first day of January 2000, the rules related to accepting regular jobs in the years 2001, 2002 and 2003 are important. ${ }^{3}$ These rules were the following. In 2001 workers were entitled to a maximum of 1800 Euros, to be paid in four equal amounts of 450 Euros, each six months after the start of the job provided the worker remained employed. ${ }^{4}$ In 2002 workers were entitled to a reemployment tax rebate of maximum 2269 Euros over a period of three years; 1361 in the first year and 454 in the second and third year. In 2003 no reemployment bonuses were paid for employment that started after January 1, 2003.

From the perspective of the welfare recipients these change in rules implies the following. Workers starting to receive welfare benefits in 2000 who found a job after at least 12 months of unemployment were entitled to a reemployment bonus of maximum 1800 Euros when that job was found in the calendar year 2001. This is a non-trivial amount equal to 1.6 times the

\footnotetext{
${ }^{3}$ These rules are national rules applying to acceptance of regular jobs. In addition to these national rules there were also municipality rules which applied to the acceptance of subsidized jobs. The entitlement regulations were the same for subsidized jobs but the amounts involved were substantially smaller.

${ }^{4}$ In 2001 welfare benefits were 1015 Euros per month for married or cohabiting couples and 508 Euros for singles. The minimum wage in 2001 was 1155 Euro, implying that for married or cohabiting welfare recipients the replacement rate for a minimum wage job was $91 \%$.
} 
monthly minimum wage. If these workers found a job in 2002 they were entitled to a tax rebate of maximum 2269 Euros. If they found a job in 2003 they were not entitled to a reemployment bonus. Workers starting to receive welfare benefits in 2001 who were unemployed for at least 12 months and found a job in 2002 were entitled to a tax rebate of maximum 2269 Euros. If they found a job in 2003 they were not entitled to a reemployment bonus. Finally, workers starting to receive welfare benefits in 2002 or 2003 were not entitled to a reemployment bonus. The changes in the entitlement rules across inflow cohorts and within cohorts over calendar time allows us to identify whether or not the reemployment bonuses affected the job finding rates.

There is a fundamental difference between the U.S. experiments and the setup of the Rotterdam bonus system. Whereas in the U.S. experiments a bonus was paid to workers who found a job quickly, in Rotterdam welfare recipients became entitled for a reemployment bonus after being unemployed for at least one year. The main reason for this was fear of dead weight loss, i.e. workers taking up bonuses who would have found a job anyway. This set-up creates disincentives for workers who are close to being unemployed for one year: why accept a job shortly before becoming entitled to a reemployment bonus? In our empirical analysis we investigate whether such an anticipation effect exists. In our analysis there are three issues we have to deal with. First, there is a potential "anticipation" effect: welfare recipients who were close to being unemployed for a year - and thus not yet entitled to a bonus - may have postponed starting on the job until they were unemployed for more than a year and would be entitled to a bonus. Second, people who were entitled may not have applied for a bonus. Third, if a job was lost within six months individuals who thought at the start of their job that they might be entitled to a bonus were not entitled after all. This means that job search behavior by welfare recipients may have been driven more by entitlement than by actual receipt of the bonus. Therefore, and because of data limitations discussed below, we analyze the effect of being entitled to a bonus. In our analysis we identify the potential effect of a reemployment bonus by comparing the pattern of duration dependence of workers who were entitled to a reemployment bonus with the pattern of those who were not entitled. We distinguish between an "anticipation" effect in month 12 and a "treatment" effect beyond month 12 . 


\subsection{Benefit sanctions}

The main reason to impose benefit sanctions is noncompliance with job search guidelines. Other reasons are because of administrative infringements like returning late from holiday, filling in forms incorrectly, etc. The procedure of imposing a sanction consists of two steps. In the first step, it is established that a welfare recipient does not comply with the guidelines of the welfare agency. Information on possible offenses can come from the monthly form a welfare recipient has to fill in, or from conversations between the employees of the welfare agency and the welfare recipient. It is also possible that the public employment office informs the welfare agency about a lack of job search activity. In the second step of the sanction procedure, it is decided whether or not the noncompliance will be punished. Noncompliance does not always lead to a sanction. ${ }^{5}$ Local or district governments are responsible for the payment of welfare benefits, but the national government has set binding rules and procedures concerning the imposition of sanctions. However, these rules do not imply that the sanctions are imposed automatically or fully objectively. The case workers of the welfare agency have some discretion to interpret the rules. According to the procedures, the decision to impose a sanction on a particular welfare recipient is taken by the local welfare employee after consulting a so called "decision maker". The decision maker checks the proposal to make sure that all the right legal steps in the procedure have been taken. The employee of the welfare agency takes the state of the local labor market into account when deciding whether or not a sanction should be imposed. Furthermore, conditional on noncompliance with the guidelines, the decision to impose a sanction also depends on characteristics of the welfare recipients like attitude, appearance and motivation. These are all characteristics that are unobserved by the researcher trying to investigate the effect of sanctions.

The period between the establishment of noncompliance by the case worker of the welfare agency and the imposition of a sanction is usually one to two months. Many sanctions are treated in an administrative way for example when welfare recipients do not provide information about their search efforts. The municipality has the possibility of sending a written warning to a welfare recipient, especially for failing to meet administrative obligations.

\subsection{Data}

Our data contain 28,039 individuals between 16 and 60 year old who started collecting welfare benefits in Rotterdam between January 1, 2000 and August 1, 2003. In total, the data

\footnotetext{
${ }^{5}$ However, in case of severe fraud, the welfare agency may decide to pursue legal prosecution.
} 
Table 1: Summary statistics

\begin{tabular}{lcc}
\hline \hline & Men & Women \\
\hline Number of individuals & 15,350 & 12,689 \\
Number of spells & 17,055 & 13,472 \\
Outflow to work & $49.2 \%$ & $40.4 \%$ \\
Spells with sanction & $12.5 \%$ & $7.7 \%$ \\
Spells with warnings $\left.{ }^{a}\right)$ & $1.7 \%$ & $1.3 \%$ \\
& & \\
Age (in years) & 32.5 & 31.0 \\
Children & $14.1 \%$ & $56.5 \%$ \\
Non-Dutch & $15.0 \%$ & $9.9 \%$ \\
Married & $13.1 \%$ & $4.7 \%$ \\
& & \\
Reason inflow: & & \\
Leaving school & $6.6 \%$ & $10.3 \%$ \\
End work & $16.5 \%$ & $11.6 \%$ \\
End UI benefits & $14.0 \%$ & $8.4 \%$ \\
Other reasons & $62.8 \%$ & $69.7 \%$ \\
\hline \hline
\end{tabular}

a) On warnings only information after July 2002 is available; the percentages refer to spells which originated after July 2002. The sanction rate for these spells is $7.5 \%$ and $5.1 \%$ for men and women, respectively.

include 30,527 welfare spells. There are thus some individuals with multiple spells, but the vast majority of the individuals only experienced a single period of receiving welfare benefits within the observation period, which ends September 1, 2003. For each individual we observe the day of inflow and the reason of inflow into welfare. For individuals leaving welfare before the end of the observation period, we observe the day of leaving welfare and the reason for leaving welfare. If a sanction is given during the welfare period, we observe the exact day at which a sanction is imposed. We do not have information about the job the welfare recipients finds after leaving welfare. Therefore we cannot analyze how benefit sanctions and reemployment bonuses affect the quality of the post-unemployment job. ${ }^{6}$

About $44 \%$ of the observed welfare spells describe women. Women leave welfare less often than men because of finding work. Table 1 show that about $40 \%$ of the welfare spells of women are observed to exit into work, while this is the case for around $49 \%$ for men. In Figure 1 we show the empirical survivor functions for men and women. In the figures we stratify by year of starting collecting welfare benefits. There are two striking features. First, women are more likely stay in welfare for a longer period. And second, the exit rate to work is lower for the cohort entering welfare in 2002 compared to 2000 and 2001. The latter is probably

\footnotetext{
${ }^{6}$ In the data we observe some individuals experiencing multiple welfare spells, which would potentially allow us to analyze time-out-of-welfare as an indicator of the quality of the job. However, in practice the number of individuals with multiple spells is too low to perform such an analysis. As we describe in more detail below, the availability of multiple spells does help us in the identification of our empirical model.
} 
the consequence of business cycle effects. Figure 2 shows that our observation period was characterized by a (nationwide) slow-down of GDP growth in 2000 and 2001, and no growth in 2002 and 2003. Furthermore, in Rotterdam the number of vacancies over the number of non-employed job seekers decreased.
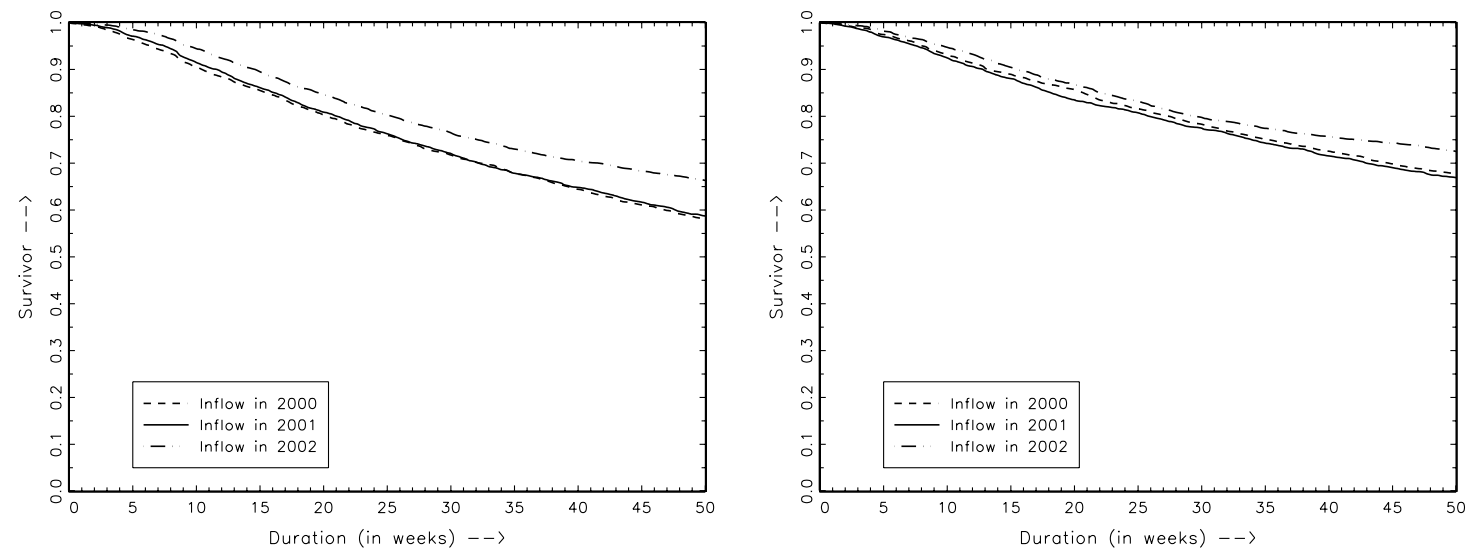

Figure 1: Kaplan-Meier estimate for men (left) and women (right) for different inflow cohorts.
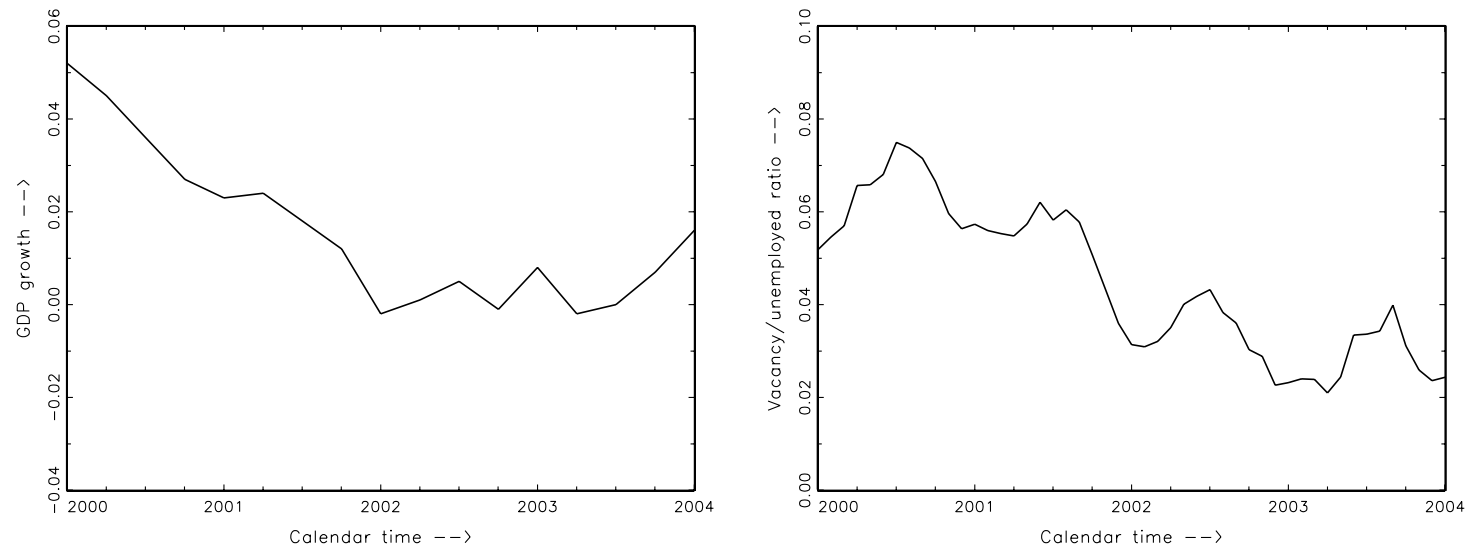

Figure 2: Business cycle indicators.

Table 1 shows that even though men, on average, have shorter welfare spells than women, they are more likely to be punished with a sanction. Male and female welfare recipients also differ substantially in individual characteristics. The age profile is similar, but women are much more likely to have children and are less likely to be married. Indeed, a substantial share of the women are single mothers. Also the reason for entering welfare differs somewhat, although for both men and women the "other" category is the largest. This category includes, 
for example, people entering after a divorce, after receiving an asylum, after losing their disability benefits or stopping to work as self-employed. Men are, however, more likely to enter welfare after some period of work (either directly or via UI).

Our data also include some information on actual payments of reemployment bonuses. Recall that until 2001 there were only reemployment bonuses, which were specific to Rotterdam. At the end of 2001 also nationwide reemployment bonuses were introduced, which partly replaced the reemployment bonuses specific to Rotterdam. And in 2002 the bonuses were replaced with a tax rebate. Our data contain two files, one with the days of payment of the bonuses specific to Rotterdam and one with the days of payments of the nationwide bonuses. The data contain only an indicator to which individual the bonus was paid, but not to which spell the bonus was tight.

Recall that individuals had to apply for receiving the bonus. We tried to match the bonuses to specific spells and also determined eligibility for a bonus (based on minimum one year of collecting welfare, exit to work and not returning to welfare within six months). Since we do not have any information about tax records we can not observe which individuals requested the tax rebate. Therefore, we focus on the bonuses in the year 2001 in which there were mainly bonuses provided by Rotterdam. Due to the data, in 2000 there were no welfare spells yet exceeding one year. In 2001, there were 312 eligible spells, of which 118 actually had a bonus payment. This is about $38 \%$. It should be stressed that this is the take-up rate for the first bonus-payment. Some bonuses were paid in made in multiple tranches upon still having work.

\section{Model}

In this section we provide the empirical model for estimating the effects of benefit sanctions and reemployment bonuses on the job finding rate of welfare recipients. For this purpose, we use a continuous time duration model, which describes the transition from welfare to work.

In the identification of the model we exploit the fact that the exact timing of a sanction is unanticipated by welfare recipients. No anticipation implies that before the actual moment of getting a sanction imposed, the sanction does not have any effect on reemployment. Only at the moment of imposing a sanction, the exit rates to work jumps. This is the so called ex post sanction effect. No anticipation does not mean that sanctions are given randomly (conditional on observed characteristics). Welfare recipients may know if and when they are 
exposed to high risks of getting a sanction. ${ }^{7}$ This approach has been used before by Abbring et al. (2005), Lalive et al. (2005) and Van den Berg et al. (2004). The details of the identification are discussed at length in Abbring and Van den Berg (2003).

We cannot use a similar approach for estimating the effects of reemployment bonuses. Welfare recipients are informed if and when they are entitled to receiving a bonus upon finding work. However, the rules change over time, and only part of the welfare recipients are affected by the reemployment bonuses. This allows us to distinguish between the effect of the reemployment bonus and calendar time effects. Like in difference-in-difference estimation the identification of the effect of the reemployment bonuses thus hinges on the assumption of a common trend for affected and non-affected welfare recipients.

Recall that the data describe individuals who started collecting welfare benefits between January 1, 2000 and August 1, 2003. Consider an individual entering welfare at date $\tau_{0}$, who has been unemployed for $t$ days. The exit rate from welfare to work depends not only on calendar time $\tau_{0}+t$ and the elapsed duration of welfare $t$, but also on observed individual characteristics $x$ and unobserved characteristics $v_{u}$. Furthermore, the transition rate from welfare to work can be affected by whether or not a sanction has been imposed on the welfare recipient. Let $t_{s}$ denote the elapsed duration op imposing a sanction, and $I\left(t>t_{s}\right)$ is thus an indicator if after $t$ days of welfare the individual has been punished by a sanction. For this welfare recipient the reemployment rate is described by the mixed proportional hazard rate

$$
\theta_{u}\left(t \mid x, \tau_{0}, t_{s}, v_{u}\right)=\lambda_{u}(t) \psi_{u}\left(\tau_{0}+t\right) \exp \left(x \beta_{u}+\delta I\left(t>t_{s}\right)+\gamma\left(t \mid \tau_{0}\right)+v_{u}\right)
$$

where $\lambda_{u}(t)$ is true (piecewise constant) duration dependence and $\psi_{u}\left(\tau_{0}+t\right)$ are genuine calendar time effects modeled by dummies for each quarter.

The parameter $\delta$ is the ex-post effect of imposing a sanction, this parameter describes how the hazard rate shifts at the moment a sanction is imposed on the welfare recipients. The other parameter of interest is $\gamma\left(t \mid \tau_{0}\right)$, which is the effect of promising a reemployment bonus. Recall from Subsection 3.1 that individuals are entitled to receiving a reemployment bonus if they find work after more than one year of collecting welfare benefits (and do not return to unemployment within half a year). However, the size of the bonuses has been changed over the years. Changes were always implemented on January 1. Furthermore, on January 1, 2003 the bonus schemes were stopped. This implies that $\gamma\left(t \mid \tau_{0}\right)$ is zero if $\tau_{0}+t$ exceeds January $1,2003$.

\footnotetext{
${ }^{7}$ To the extent that welfare recipients want to avoid a benefit sanction they may change their behavior before such a sanction is imposed. This is the so called ex ante sanction effect.
} 
We allow reemployment bonuses to have two effects. First, there can be a true incentive effect for those who are entitled to collecting the bonus when finding work. These are the individuals collecting welfare for at least one year. Second, there can be an anticipation effect. This effect arises if individuals close to one year of welfare reduce job search to avoid finding work, or maybe delay accepting a job until becoming entitled to the reemployment bonus. We, therefore, specify the effect of the reemployment bonus as

$$
\gamma\left(t \mid \tau_{0}\right)= \begin{cases}0 & \text { if } t \leq 11 \text { months or } \tau_{0}+t \geq \text { January } 1,2003 \\ \gamma_{0, \tau_{0}+t} & \text { if } 11 \text { months }<t \leq 12 \text { months and } \tau_{0}+t<\text { January } 1,2003 \\ \gamma_{1, \tau_{0}+t} & \text { if } t>12 \text { months and } \tau_{0}+t<\text { January } 1,2003\end{cases}
$$

The parameter $\gamma_{0, \tau_{0}+t}$ measures the anticipation effect of the bonuses. This implies that between 11 and 12 months of unemployment the model allows individuals to anticipate that they might get a bonus when finding work after 12 months. In Subsection 5.2 we investigate the importance of choosing 11 months as the start of the anticipation effect. The parameter $\gamma_{0, \tau_{0}+t}$ is different for each (calendar) year. This is also the case for $\gamma_{1, \tau_{0}+t}$ which measures the incentive effects of the bonuses after 12 months of unemployment. The reason is that the size of the reemployment bonuses varied over the years.

The key identification problem is that we have to distinguish between both between true duration dependence $\lambda_{u}(t)$ and the bonus effects, and between calendar time effects $\psi_{u}\left(\tau_{0}+t\right)$ and the bonus effects. First, we exploit that from January 1, 2003 welfare recipients were no longer entitled to receiving reemployment bonuses. This implies that both $\gamma_{0, \tau}$ and $\gamma_{1, \tau}$ should be zero if $\tau_{0}+t$ exceeds January 1, 2003. Changes is reemployment rates over the duration of unemployment in 2003 are thus only the consequences of true duration dependence.

Second, to separate true calendar time effects from the effects of reemployment bonuses, we assume that anticipation effects do not start immediately after entering welfare. Changes over exit rates to work over calendar time shortly after entering welfare are thus only the consequence of true calendar time effects, while such changes for longer durations are the consequence of both calendar time effects and changes in bonus effects. The identifying assumption is thus proportionality of duration dependence and calendar time effects in the exit rate to work, which is equivalent to the common trend assumption in difference-indifference estimation.

An alternative identification strategy would be to focus on exact dates at which the rules for the reemployment bonuses changed. By considering reemployment rate just below and just after the policy change, we could identify the effect of the policy change (e.g. Van den Berg 
et al., 2010). Such an approach is equivalent to regression discontinuity and would require smoothness in calendar-time effects around the moment of the policy change. Applying this approach would not be very attractive in our case. First, because outflow rates from welfare are low, and we thus observe too few exits from welfare in a small interval around the thresholds (in particular when focussing on welfare recipients with spells exceeding one year). Furthermore and maybe more important is that we lack information about the exact moment at which welfare recipients were informed. ${ }^{8}$

Sanctions are not given randomly (and also not conditional on observed characteristics). This suggests a correlation between the timing of a sanction $t_{s}$ and unobserved characteristics $v_{u}$. To take account of this endogeneity problem, we jointly model the timing of imposing a sanction with exit to work. The rate at which sanctions are imposed on individuals is given by

$$
\theta_{s}\left(t \mid x, \tau_{0}, v_{s}\right)=\lambda_{s}(t) \psi_{s}\left(\tau_{0}+t\right) \exp \left(x \beta_{s}+v_{s}\right)
$$

Again $\lambda_{s}(t)$ is genuine duration dependence, and $\psi_{s}\left(\tau_{0}+t\right)$ are calendar-time effects. The calendar-time effects are again modeled using dummy variables for each quarter. To account for selectivity in imposing sanctions the unobserved components of the reemployment rate and the sanction rate $-v_{u}$ and $v_{s}$ - are allowed to be correlated to each other.

We take the joint distribution of the unobserved heterogeneity terms $v_{u}$ and $v_{s}$ to be bivariate discrete with two unrestricted mass-point locations for each term. Let $v_{u}^{a}, v_{u}^{b}, v_{s}^{a}$ and $v_{s}^{b}$ denote the points of support of $v_{u}$ and $v_{s}$, respectively. The associated probabilities are denoted as follows:

$$
\begin{array}{ll}
\operatorname{Pr}\left(v_{u}=v_{u}^{a}, v_{s}=v_{s}^{a}\right)=p_{1} & \operatorname{Pr}\left(v_{u}=v_{u}^{b}, v_{s}=v_{s}^{a}\right)=p_{3} \\
\operatorname{Pr}\left(v_{u}=v_{u}^{a}, v_{s}=v_{s}^{b}\right)=p_{2} & \operatorname{Pr}\left(v_{u}=v_{u}^{b}, v_{s}=v_{s}^{b}\right)=p_{4}
\end{array}
$$

with $0 \leq p_{i} \leq 1$ for $i=1, \ldots, 4$, and $p_{4}=1-p_{1}-p_{2}-p_{3}$.

Finally, we parameterize the pattern of duration dependence. We take both $\lambda_{u}(t)$ and $\lambda_{s}(t)$ to have a piecewise constant specification,

$$
\lambda_{i}(t)=\exp \left(\sum_{j=1,2, \ldots} \lambda_{i j} I_{j}(t)\right) \quad i=u, s
$$

where $j$ is a subscript for time intervals and $I_{j}(t)$ are time-varying dummy variables that are one in consecutive time intervals. Note that with an increasing number of time intervals any duration dependence pattern can be approximated arbitrarily closely.

\footnotetext{
${ }^{8}$ There is some evidence that in some years welfare recipients were informed about the change in the bonus scheme after it was already implemented.
} 
To estimate the parameters in our model, we use maximum likelihood estimation. It should be noted that our data contain some multiple spells of collecting welfare of the same individuals. We exploit this by assuming that within different spells, the unobserved heterogeneity term of an individual remains the same. It is well known that information on multiple spells improves the identification of the distribution of unobserved heterogeneity.

Specifying the loglikelihood function requires that we fist introduce some additional notation. Consider a data set including $N$ individuals, and individual $i=1, \ldots, N$ experiences $J_{i}$ spells of collecting welfare benefits. Of course, not during all spells a sanction imposed. The variable $d_{i j}^{s}$ describes if a sanction was imposed during spell $j$ of individual $i$. If no sanction was imposed the duration until imposing a sanction $t_{s, i j}$ equals the observed duration of the welfare spell $t_{i j}$. Finally, the indicator $d_{i j}^{u}$ denotes if a welfare spell ended in finding work. The loglikelihood function equals

$$
\begin{gathered}
\mathcal{L}=\sum_{i=1}^{N} \log \left\{\sum_{v_{u}, v_{s}} \prod_{j=1}^{J_{i}} \theta_{u}\left(t_{i j} \mid x_{i j}, \tau_{0, i j}, t_{s, i j}, v_{u}\right)^{d_{i j}^{u}} \exp \left(-\int_{0}^{t_{i j}} \theta_{u}\left(t \mid x_{i j}, \tau_{0, i j}, t_{s, i j}, v_{u}\right) d t\right)\right. \\
\left.\theta_{s}\left(t_{s, i j} \mid x_{i j}, \tau_{0, i j}, v_{s}\right)^{d_{i j}^{s}} \exp \left(\int_{0}^{t_{s, i j}} \theta_{s}\left(t \mid x_{i j}, \tau_{0, i j}, v_{s}\right) d t\right) \operatorname{Pr}\left(v_{u}, v_{s}\right)\right\}
\end{gathered}
$$

Note that this loglikelihood function indeed imposes that all spells of one individual share the same unobserved heterogeneity term. We optimize this logelikelihood function over all unknown parameters.

\section{Estimation results}

\subsection{Parameter estimates}

Table 2 provides the parameter estimates of the baseline model. We estimate the model separately for men and women. For both men and women we find only two points of support in the distribution of the unobserved heterogeneity. This implies that conditional on observed characteristics there is perfect negative correlation between the unobserved heterogeneity in the exit rate to work and the sanction rate. In both case the two points describe that individuals with a higher exit rate to work have a lower sanction rate. However, for men the difference in sanction rate between welfare recipients with a high and low rate is very small. For both men and women most probability mass is located to welfare recipients with a low exit rate and high sanction rate, $72 \%$ and $59 \%$, respectively for men and women.

The main parameters of interest are the effects of the reemployment bonuses and the 
Table 2: Estimation results of the baseline model

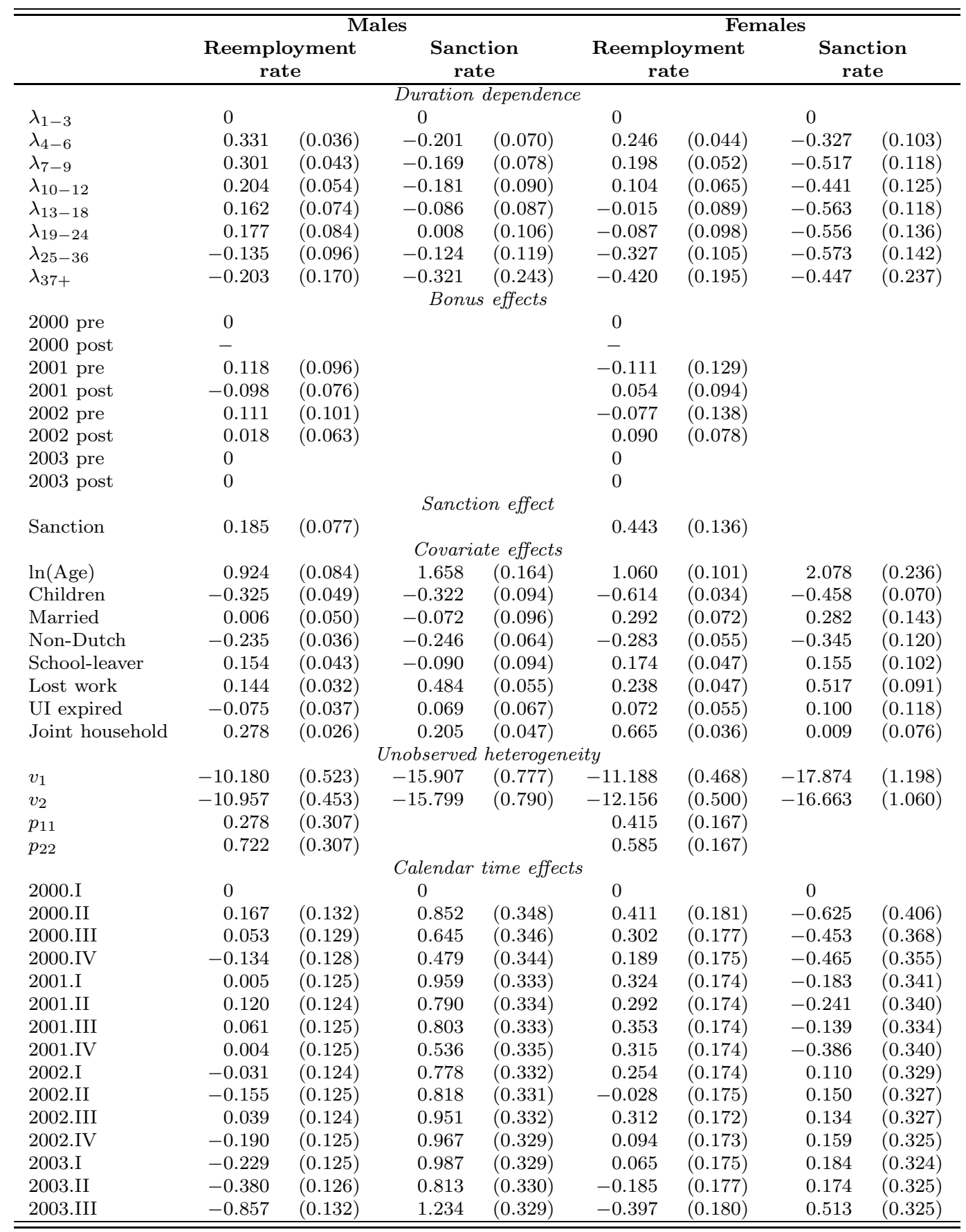


Table 3: Simulation experiments showing job finding rate within two years after entering welfare on January 1, 2001

\begin{tabular}{lcc}
\hline \hline & Males & Females \\
\hline No bonuses, and no sanction & $62.5 \%$ & $48.9 \%$ \\
Bonus, but no sanction & $62.9 \%$ & $49.9 \%$ \\
No bonus, but sanction after one year & $65.4 \%$ & $54.9 \%$ \\
Bonus and sanction after one year & $65.9 \%$ & $56.2 \%$ \\
\hline \hline
\end{tabular}

benefit sanctions. First, sanctions do have a positive and significant effect on reemployment. The effect is more than twice as large for women than for men. Second, the effect of the bonuses is insignificant. For women the parameters have the expected sign, but the effects are small (in particular when compared to the sanction effects). For men the estimated coefficients do not even have the expected sign.

A sanction increased the exit rate to work of men by about $20 \%$. For women this is about $56 \%$. Our findings for women are well in the range of previous studies such as Abbring et al. (2005) finding an increase from 35 to 100\%, Lalive et al. (2005) finding an increase of $45 \%$ and Svarer (2007) finding an increase of 50\%. Our findings for men are relatively small compared to these previous studies. It should, however, be noted that sanctions are more often applied on men than on women. A man who did not find work within six months after entering welfare has a $6.0 \%$ probability of having a sanction imposed in this period, while this is only $3.5 \%$ for women. Also, in recent years benefit sanctions were used more often than in the 1990s which might reduce the effects and explain the smaller effect compared to Van den Berg et al. (2004). Furthermore, men are more likely to leave welfare than women. If no sanction would have been imposed, around $21.0 \%$ of the men and $17.3 \%$ of the women leave welfare within six months. If after three months a sanction is imposed, the probability that a man leaves welfare within six months increases from 21.0 to $23.0 \%$. For women such a sanction would increase the reemployment from 17.3 to $21.5 \%$.

To get some insight in the effect of the reemployment bonus, we simulate the model assuming that all individuals enter welfare on January 1, 2001 and focus on finding work within two years. Table 3 shows the results for these simulations. If there would not be any reemployment bonuses and there would not be any sanction applied during the first two years of collecting welfare benefits, $48.9 \%$ of the women and $62.5 \%$ of the men would find work within two years. The reemployment bonus scheme slightly increases this to $49.9 \%$ and $62.9 \%$ for women and men, respectively. These effects are small, but in line with previous reemployment 
bonus studies that also find small effects. Imposing a sanction after one year of welfare causes a much more substantial increase in the reemployment rate, i.e. the reemployment rates increases to $54.9 \%$ and $65.4 \%$ for women and men respectively. Finally, the two financial incentives combined increase for women reemployment from $48.9 \%$ to $56.2 \%$ and for men from $62.5 \%$ to $65.9 \%$.

There are a few reasons why bonuses might have not been very effective in stimulating reemployment. First, recall from Section 3.3 that the take-up rate of the first bonus payment is about $38 \%$. This is not because welfare recipients are unaware about the reemployment bonus scheme. Caseworkers are instructed to inform welfare recipients about the existence of the scheme, and welfare recipients also receive written information. Furthermore, at the moment of a change in the scheme, all welfare recipients received a letter. Of course, it might be that the annual policy changes caused welfare recipients to not completely understand the incentives. We return to this issue in Section 6.

Both for men and for women the exit rate to work is highest between four and six months after entering welfare. After being on welfare for six months the exit rate to work decreases monotonically. It should be noted that the decrease in exit rate to work is more rapidly for women than for men. For both men and women the sanction rate is highest during the first three months on collecting welfare benefits. After this period there is no clear pattern in the duration dependence.

The covariate effects of the observed individual characteristics on the exit rate to work are very similar for men and women. The exit rate to work is higher for older individuals, individuals without children, non-singles, individuals with a Dutch nationality, and those who entered welfare after leaving school and after their unemployment insurance benefits expired.

The calendar time effects show that at the end of 2002 reemployment rates started to drop. It should be noted that our observation period is characterized by a reducing GDP growth rate since the end of 1999. In the fourth quarter of 1999 the GDP growth rate was almost $6 \%$ and this reduced to $0 \%$ in the first quarter in 2002.

\subsection{Sensitivity analysis}

In this section we present a few sensitivity analyses to investigate the robustness of our estimation results with respect to the model specification. We focus on the importance of controlling for selection in imposing sanctions, the specification of business cycle effects, anticipation effects for reemployment bonuses and the nature of the exit state. Table 4 shows 
the results of these sensitivity analyses for the effects of bonuses and sanctions.

In the first sensitivity analysis, we ignore that sanctions are imposed selectively. This implies that there is no correlation in the unobserved heterogeneity terms in the reemployment rate and the sanction rate. The reemployment rate can thus be estimated without jointly estimating the sanction rate. It should be noted that it does not mean that unobserved heterogeneity is absent. The upper part of Table 4 presents the estimated sanction and bonus effects. The only substantial difference is that the size of the sanction effect for women reduces to about half the value. Compared to the results for men, the baseline model for women had much more dispersion in unobserved heterogeneity. This explains why we only find a substantial effect for women.

The identification of the bonus effects relies on accounting correctly for calendar-time effects. In the baseline model, we included dummy-variables for each quarter. We replace these by business cycle indicators. In particular, we use nationwide GDP growth and as local business cycle indicator the number of job vacancies over the number of non-employed job seekers. Job vacancies registered at the local public employment office, are estimated to be about $25 \%$ of all vacancies, but they are mainly the vacancies for low-skilled jobs, most relevant for welfare recipients. The number of non-employed job-seekers are those registered at the public employment office. Additionally, we include year dummies and seasonal dummies. The second part of the Table 4 shows the estimated effects of sanctions and reemployment bonuses are very similar as in the baseline model.

In the next sensitivity analysis we consider the length of the anticipation period prior to becoming eligible for the reemployment bonus. In the baseline model, we imposed that one month prior to becoming eligible, welfare recipients can change their behavior. In the sensitivity analysis we extend this to two months. As can be seen in the second part of Table 4, both for men and women, the estimated anticipations effects become much smaller compared to the baseline model. This confirms that anticipation of welfare recipients is not present more than one month before becoming eligible for the reemployment bonus.

In the final sensitivity analysis, we consider the reason for leaving welfare. In the earlier analyses we simply modeled any exit from collecting welfare. In the sensitivity analysis, we only focus on finding paid work and all other exit channels are considered as exogenously right-censored. It should, however, be stressed that registering the correct reason for exit is difficult for the welfare agency. In the data, there are many unknown destinations and individuals moving abroad or to other municipalities. These might to a large extent be 
Table 4: Sensitivity analyses.

\begin{tabular}{|c|c|c|c|c|}
\hline & \multicolumn{2}{|c|}{ Males } & \multicolumn{2}{|c|}{ Females } \\
\hline & \multicolumn{2}{|c|}{ No selectivity } & \multirow{3}{*}{0.206} & \multirow{3}{*}{$(0.067)$} \\
\hline Sanction on exit & 0.169 & $(0.039)$ & & \\
\hline Bonus effects & & & & \\
\hline 2000 pre & 0 & & 0 & \\
\hline 2000 post & - & & - & \\
\hline 2001 pre & 0.118 & $(0.096)$ & -0.113 & $(0.129)$ \\
\hline 2001 post & -0.097 & $(0.076)$ & 0.047 & $(0.094)$ \\
\hline 2002 pre & 0.111 & $(0.101)$ & -0.077 & $(0.138)$ \\
\hline 2002 post & 0.018 & $(0.063)$ & 0.084 & $(0.078)$ \\
\hline 2003 pre & 0 & & 0 & \\
\hline 2003 post & 0 & & 0 & \\
\hline \multicolumn{5}{|c|}{ Polynomial in calendar time } \\
\hline $\begin{array}{l}\text { Sanction on exit } \\
\text { Bonus effects }\end{array}$ & 0.172 & $(0.070)$ & 0.432 & $(0.136)$ \\
\hline 2000 pre & 0 & & 0 & \\
\hline 2000 post & - & & - & \\
\hline 2001 pre & 0.114 & $(0.095)$ & -0.109 & $(0.129)$ \\
\hline 2001 post & -0.049 & $(0.075)$ & 0.103 & $(0.093)$ \\
\hline 2002 pre & 0.107 & $(0.100)$ & -0.075 & $(0.138)$ \\
\hline 2002 post & 0.026 & $(0.062)$ & 0.097 & $(0.078)$ \\
\hline 2003 pre & 0 & & 0 & \\
\hline 2003 post & 0 & & 0 & \\
\hline \multicolumn{5}{|c|}{ Anticipation during two months } \\
\hline $\begin{array}{l}\text { Sanction on exit } \\
\text { Bonus effects }\end{array}$ & 0.186 & $(0.078)$ & 0.443 & $(0.136)$ \\
\hline 2000 pre & 0 & & 0 & \\
\hline 2000 post & - & & - & \\
\hline 2001 pre & 0.071 & $(0.080)$ & 0.014 & $(0.101)$ \\
\hline 2001 post & -0.097 & $(0.076)$ & 0.063 & $(0.094)$ \\
\hline 2002 pre & 0.087 & $(0.083)$ & -0.015 & $(0.109)$ \\
\hline 2002 post & 0.022 & $(0.063)$ & 0.093 & $(0.079)$ \\
\hline 2003 pre & 0 & & 0 & \\
\hline 2003 post & 0 & & 0 & \\
\hline \multicolumn{5}{|c|}{ Only registered exit to work } \\
\hline $\begin{array}{l}\text { Sanction on exit } \\
\text { Bonus effects }\end{array}$ & 0.164 & $(0.140)$ & -0.007 & $(0.170)$ \\
\hline 2000 pre & 0 & & 0 & \\
\hline 2000 post & - & & - & \\
\hline 2001 pre & 0.268 & $(0.149)$ & 0.061 & $(0.101)$ \\
\hline 2001 post & -0.199 & $(0.131)$ & -0.050 & $(0.094)$ \\
\hline 2002 pre & -0.030 & $(0.178)$ & -0.051 & $(0.283)$ \\
\hline 2002 post & 0.050 & $(0.107)$ & 0.176 & $(0.137)$ \\
\hline 2003 pre & 0 & & 0 & \\
\hline 2003 post & 0 & & 0 & \\
\hline
\end{tabular}


welfare recipients finding work but without informing the welfare agency about the reason for the outflow from the benefit system. For example, it is very difficult for a welfare recipient to move and start collecting welfare benefits in another municipality. It is more likely that a welfare recipient moved to another municipality because (s)he found work there. The bottom part of Table 4 shows the estimates of the policy parameters when exit is restricted to those reporting finding paid work. For males the results are quite in line with the earlier results, although standard errors increase substantially. The latter also happens for women, but here also parameter estimates change. In particular, the sanction effect becomes zero. This might imply that after a sanction women leave welfare for other reasons than finding work. We should, however, keep in mind that it is very difficult for the welfare agency to register the main reason for leaving welfare.

All in all, our parameter estimates are quite robust to these alternative specifications.

\section{What explains our findings?}

Our main findings are that reemployment bonuses don't seem to have worked, while benefit sanctions increased the job finding rate significantly. The latter finding is in line with previous empirical studies and is also in line with a search theoretical framework in which benefit sanctions increase the costs of remaining unemployed thus stimulating welfare recipients to find a job. However, reemployment bonuses should also increase job finding because the value of accepting a job increases. What explains the differences in our findings concerning the effects of benefit sanctions and reemployment bonuses? It could be that welfare recipients are "impatient", i.e. they assign a lower value to future benefits of job search and therefore exert less effort to find a job. In addition to this, welfare recipients may have so called hyperbolic time preferences, i.e. the are "present biased" in the sense that in the short run they discount highly while in the long run they discount less.

Della Vigna and Paserman (2005) investigate the relevance of impatience and hyperbolic discounting in job search decisions. ${ }^{9}$ They argue that workers who are more impatient search less intensively and set lower reservation wages. With normal time preferences the effect of

\footnotetext{
${ }^{9}$ There are only a few studies empirically investigating the existence of hyperbolic discounting in labor market decisions. A rare example is Fang and Silverman (2009) who investigate the relationship between time discounting and welfare program participation decisions using NLSY data. They find evidence of a presentbias and conclude that limiting the duration of welfare benefits may substantially increase employment. Under certain conditions also workfare may be useful, not only to increase employment but also increase life time utility of welfare recipients.
} 
impatience on job finding rates is unclear as the decrease in search intensity lowers the job finding rate while the lower reservation wages increase the job finding rate. With hyperbolic time preferences the search effect dominates and increases in impatience lead to lower job finding rates. Analyzing NLSY and PSID data, Della Vigna and Paserman (2005) conclude that the effect of impatience on search effort is negative and sizable; the effect of impatience on reservation wages and reemployment wages is essentially zero.

With this in mind we can explain our findings. The lack of effects from the reemployment bonuses may be related to a low take-up rate, but the low take-up rate cannot be attributed to lack of information among welfare recipients. The caseworkers made the welfare recipients aware of the existence and nature of the reemployment bonuses, the welfare recipients also received a letter at their home addresses about their eligibility for a reemployment bonus. Nevertheless, the ineffectiveness of the reemployment bonuses is not very surprising. Whereas in the US reemployment bonuses were provided at the start of unemployment spells, in Rotterdam only long-term unemployed welfare recipients were eligible for a reemployment bonus. The delay in payments might well limit the incentives from a reemployment bonus. ${ }^{10}$ In 2001 for example the maximum bonus of 1800 Euros (1.6* monthly minimum wage) is substantial, but paid in 4 equal amounts of 450 Euro, each 6 months after the start of the job. So the last payment would occur 2 years after the start on the job. The balance between short run costs in job search and long run benefits of the reemployment bonus may not be positive inducing welfare recipients not to increase their search intensity.

The effectiveness of benefit sanctions can be explained in a traditional job search model. Nevertheless, hyperbolic discounting has interesting welfare implications. Paserman (2008) argues that with hyperbolic discounting benefit sanctions might even be welfare improving for individual unemployed workers. ${ }^{11}$ He concludes that because some workers are presentbiased an optimal unemployment benefit policy takes the form of monitoring search effort, and imposing sanctions on workers who do not meet the effort threshold. The policy has a positive effect on the hyperbolic worker's long-run utility. Time-inconsistent workers may benefit

\footnotetext{
${ }^{10}$ Restricting reemployment bonuses to long-term unemployed also implies that only workers with a bad labor market position qualified. Through a process of dynamic selection the most suitable workers have probably left the welfare system before becoming eligible for reemployment bonuses.

${ }^{11}$ Paserman compares different types of labor market policies: cutting the level of unemployment benefits, shortening the duration of benefits, changing the time profile of unemployment benefits, job search assistance, monitoring search intensity, monitoring job acceptance, re-employment bonus. The different policies are evaluated from the perspective of an individual who is not currently unemployed when deciding whether to implement a change to the unemployment insurance system.
} 
particularly from policies that commit them to a higher search intensity. The implication for labor market policy is that direct assistance that forces the worker to overcome their procrastination problem and to go through the most unpleasant steps of the search process is likely to be beneficial. The government's threat to cut benefits if the welfare recipient does not exert sufficient search effort acts exactly as this desirable commitment device.

\section{Conclusions}

It is not always easy to bring unemployed back to work. Expensive active labor market programs are often not very effective. Low cost programs focusing on monitoring of unemployed workers and providing financial incentives seem to do a better job. We study the transition from welfare to work in the municipality of Rotterdam where benefit recipients were exposed to various financial incentives. Their benefits could be reduced temporarily as punishment for noncompliance with eligibility requirements. However, they could also be rewarded for "good" behavior. Once their unemployment spell lasted more than one year, they were entitled to a reemployment bonus if they found a job. In this paper we investigate how benefit sanctions and reemployment bonuses affected job finding rates of welfare recipients. In line with previous studies we find substantial effects of benefit sanctions and no effects of reemployment bonuses. Previous US based studies find positive effects of reemployment bonuses but these effects are often rather small. When comparing the incentive structure in the US bonus experiment with the reemployment bonus in Rotterdam it is not surprising that we find very small effects. Whereas in the US reemployment bonuses are paid at the start of the unemployment spell to unemployed with low short-lasting benefits, in Rotterdam reemployment bonuses were offered to unemployed workers with relatively high long-lasting benefits, earliest after one year of unemployment when the job finding rate were small anyway. In addition to this, the reemployment bonus policy in Rotterdam changed frequently such that every year a new system was in place. For researchers such variation is very helpful in identifying treatment effects, for welfare recipients these changes may have been confusing.

Apart from institutional reasons why reemployment bonuses were not as effective as benefit sanctions, our findings that a stick works while a carrot doesn't may be related to present-bias of some workers. To the extent that some welfare recipients are present-biased an incentive scheme that requires immediate search effort in exchange for delayed rewards in terms of a future bonus may not be an effective scheme. Benefit sanctions breaking the present bias by imposing immediate costs to lack of search effort might indeed be an effective and welfare 
improving scheme.

\section{References}

Abbring, J.H. and G.J. van den Berg (2003), The non-parametric identification of treatment effects in duration models, Econometrica 71, 1491-1517.

Abbring, J.H., G.J. van den Berg and J.C. van Ours (2005), The Effect of Unemployment Insurance Sanctions on the Transition Rate from Unemployment to Employment, Economic Journal 115, 602-630.

Anderson, P.M. (1992), Time-Varying Effects of Recall Expectation, a Reemployment Bonus, and Job Counseling on Unemployment Durations, Journal of Labor Economics, 10, 99-115.

Arni, P., R. Lalive and J.C. van Ours (2009), How Effective are Unemployment Benefit Sanctions? Looking Beyond Unemployment Exit, Working Paper, no. 4509, IZA, Bonn.

Bijwaard, G.E. and G Ridder (2005), Correcting for Selective Compliance in a Reemployment Bonus Experiment, Journal of Econometrics, 125, 77-111.

Bilias, Y. (2000), Sequential Testing of Duration Data: the Case of the Pennsylvania 'Reemployment Bonus' Experiment, Journal of Applied Econometrics, 15, 575-594.

Boockmann, B., S.L. Thomsen and T. Walter (2009), Intensifying the Use of Benefit Sanctions: An Effective Tool to Shorten Welfare Receipt and Speed Up Transitions to Employment? Discussion Paper No. 4580, IZA, Bonn.

Card, D. and D.R. Hyslop (2005), Estimating the Effects of a Time-limited Earnings Subsidy for Welfare-leavers, Econometrica, 73, 1723-70.

Card, D., J. Kluve and A. Weber (2009), Active Labor Market Policy Evaluations: a MetaAnalysis, Working Paper, no. 4002, IZA, Bonn.

Decker, P.T. (1994), The Impact of Reemployment Bonuses on Insured Unemployment in the New Jersey and Illinois Reemployment Bonus Experiments, Journal of Human Resources, $29,718-741$.

Decker, P.T. and C.L. O'Leary (1995), Evaluating Pooled Evidence from the Reemployment Bonus Experiments, Journal of Human Resources, 30, 534-550.

De Koning, J., P. van Nes, M. van de Kamp, M. Spijkerman (2006) Het gebruik van prikkels in de bijstand ('The use of incentives for welfare recipients'), mimeo, Erasmus University Rotterdam. 
Della Vigna, S. and M. D. Paserman (2005), Job Search and Impatience, Journal of Labor Economics, 23, 527-588.

Fang, H. and D. Silverman (2009) Time-Inconsistency and Welfare Program Participation: Evidence from the NLSY, International Economic Review, 50, 1043-1077.

Jensen, P., M. Svarer, M. Nielsen and M. Rosholm (1999), The Response of Youth Unemployment to Benefits, Incentives, and Sanctions, European Journal of Political Economy, $19,301-316$.

Kluve, J. and C.M. Schmidt (2002), Can Training and Employment Subsidies Combat European Unemployment? Economic Policy, 35, 411-448.

Kluve, J. (2010), The Effectiveness of European Active Labor Market Programs, Labour Economics, forthcoming.

Lalive, R., J.C. Van Ours and J. Zweimüller (2005), The Effect of Benefit Sanctions on the Duration of Unemployment, Journal of the European Economic Association, 3, 1386-1417.

O'Leary, C.J., R.G. Spiegelman and K.J. Kline (1995), Do Bonus Offers Shorten Unemployment Insurance Spells? Results from the Washington Experiment, Journal of Policy Analysis and Management, 14, 245-269.

O'Leary, C.J., P.T. Decker and S.A. Wandner (2005), Cost-Effectiveness of Targeted Reemployment Bonuses, Journal of Human Resources, 40, 270-279.

McVicar, D. (2008), Job Search Monitoring Intensity, Unemployment Exit and Job Entry: Quasi-experimental Evidence from the UK, Labour Economics, 15, 14511468.

Meyer, B.D. (1995), Lessons from the U.S. Unemployment Insurance Experiments, Journal of Economic Literature, 33, 91-131.

Meyer, B.D. (1996), What Have We Learned from the Illinois Reemployment Bonus Experiment? Journal of Labor Economics, 14, 26-51.

Paserman M.D. (2008), Job Search and Hyperbolic Discounting: Structural Estimation and Policy Evaluation, Economic Journal, 118, 1418-1452.

Svarer, M. (2007), The Effect of Sanctions on the Job Finding Rate: Evidence from Denmark, IZA Discussion Paper 3015.

Van den Berg, G.J., A. Bozio and M. Costa Dias (2010), Policy Discontinuity and Duration Outcomes, mimeo. 
Van den Berg, G.J., B. van der Klaauw and J.C. van Ours (2004), Punitive Sanctions and the Transition Rate from Welfare to Work, Journal of Labor Economics, 22, 211-241.

Van den Berg, G.J. and J. Vikström (2009), Monitoring Job Offer Decisions, Punishments, Exit to Work, and Job Quality, IFAU Working Paper 2009:18.

Woodbury, S.A. and R.G. Spiegelman (1987), Bonuses to Workers and Employers to Reduce Unemployment: Randomized Trials in Illinois, American Economic Review, 77, 513-530. 